\author{
Journal of Hospitality, Leisure, Sport \& Tourism Education \\ Vol. 1, No. 2. \\ ISSN: 1473-8376 \\ www.hlst.Itsn.ac.uk/johlste
}

\title{
University Hospitality Education for International Management: A Case of Wasted Opportunities?
}

\author{
Diane Seymour (dseymour@brookes.ac.uk) \\ Oxford Brookes University \\ Oxford, OX3 OBP, United Kingdom. \\ Panikkos Constanti \\ Intercollege, Cyprus. \\ () Journal of Hospitality, Leisure, Sport and Tourism Education
}

\begin{abstract}
In recent years, universities in the UK have developed recruitment strategies which have transformed the cultural context within which all students learn. Hospitality management degree programmes aim to provide future managers who possess the necessary skills to operate in an increasingly international industry. This article draws on two pieces of qualitative research to consider how far the experience of studying in a culturally diverse context enables students to develop the intercultural competencies necessary for managers in a global economy. Recommendations for future practice are made which would provide both host and international students with a learning environment which would better prepare them for the realities of managing diversity in the contemporary hospitality industry.
\end{abstract}

Keywords: intercultural competence; effective management; student experience

\section{Introduction}

The growth of international business, together with the demographic and social changes which have occurred in most advanced industrial economies, has led to increased interest in the effective management of a culturally diverse workforce. In this context, intercultural competence (the ability to function effectively with those from different cultural backgrounds) is crucial (Brislin, 1986). At first sight, then, the increase in the recruitment of international students into the UK tertiary education system in recent years provides an opportunity to develop the skills in intercultural communication and cultural sensitivity which are increasingly crucial for effective management in the hospitality industry. In this article, the literature on intercultural competence and that on the international student experience is discussed. Following on from this, the experiences of undergraduates from a range of cultural backgrounds studying programmes in hospitality management at a 'new' British university are explored though two pieces of qualitative research. The discussion of the research has two objectives.

Diane Seymour is a sociologist and her research interests include emotional labour, cultural diversity and the sociology of food. She has published articles on the international student experience, emotional labour, the sociology of the meal and on the occupational profile of French Hotel managers. She is responsible for leading learning, teaching and assessment in the School of Hotel and Restaurant Management and is International Student Tutor in the School as well contributing to undergraduate and postgraduate teaching and supervision. 
First, to examine whether the teaching and learning experience for both the international students and the host country students encourages the development of cultural sensitivity among all students. Second, to consider what can be done to encourage the development of intercultural competence in our students so that they will be better prepared for careers in a global economy.

\section{Intercultural competence}

The literature on intercultural competence, or effectiveness, has largely been developed from studies of expatriate success or failure, rather than from studies of multicultural workforces within a particular society (Tung, 1984; Brewster and Harris, 1999). Clearly there may be significant differences between the experiences of a manager required to manage a diverse workforce on his or her 'home ground' and those of a manager sent abroad. However, by far the most frequent reason cited for failure in the case of expatriate managers is their lack of intercultural effectiveness (Tung 1988; Black and Porter 1990), and it seems unlikely that managers who are based in their home countries are any more skilled in this regard.

A review of this literature reveals two recurring themes. Firstly, though specific knowledge of, or experience in, a different culture may be useful, it does not in itself guarantee intercultural competence. Contact does not always produce positive attitudes and may in fact reinforce negative stereotypes (Amir, 1969; O’Driscoll et al., 1983). Trompenaars and Woolliams (1999) emphasise the importance of the reconciliation of cultural differences and values as an essential feature in moving contact and experience into the positive development of intercultural competence. Secondly, although it is argued that cross-cultural sensitivity can be developed and enhanced by training (Brislin et al., 1986; Mendenhall and Oddou, 1985; Trompenaars and Woolliams, 1999; Harris and Brewster, 1999), the literature points to a serious neglect in the development of these skills. Both of these points are important as they suggest that intercultural competence could be developed very effectively within universities, particularly those which recruit from a diverse culture base.

Communicative sensitivity seems to be the dimension most often emphasised in the literature as being crucial for intercultural competence (Ruben, 1976). It refers to two aspects of behaviour: the ability to interact effectively with those whose cultural rules are different from one's own and the ability to display the appropriate communicative behaviour (Brislin, 1986). This includes the ability to deal with misunderstandings, interpersonal conflict, and to develop communicative flexibility. In any society there are powerful elites which express the dominant culture. Even though in many Western countries there has been an attempt to move towards a more multicultural approach, in most countries organisations are influenced by the culture of these elites. Members of these groups are overrepresented at the higher end of the hierarchies and their values, knowledge, ways of talking and writing and standards of appropriate behaviour are seen as the standard for the whole society and of organisations within it (Knapp et al., 1987). These values come to represent 'the way things are' and to guide management activities such as selection and appraisal criteria, promotion choices and so on. In a culturally diverse workforce what will be considered as appropriate behaviour may vary between the diverse cultural groups in a way which leads to the unconscious disadvantaging of some categories of the workforce (Jupp, 1992). Developing intercultural competence thus requires the development of communicative skills which enable a manager to disentangle differences in communicative style and assumptions from competence or lack of it on the job.

British universities are of course, themselves largely staffed by members of the British cultural elite and therefore face similar difficulties in making fair evaluations of those students who do not share this cultural background (Chen and DiTomaso, 1997). Despite efforts to broaden access, the recruitment of home (UK) students is also largely from the cultural dominant elite and so these students may share the dominant communicative style. Many British universities, faced with the implications of their increasing recruitment of international students have had to decide whether to adopt an ethnocentric or a polycentric model for their curricula and methods of study and assessment. The university examined in this research has adopted a polycentric approach, and the latter part of this article investigates how far it has been successful in doing this through the examination of the 
teaching and learning experience of students in the School of Hotel and Restaurant Management. The development of intercultural competence in undergraduate hospitality management students would seem to be contingent on the extent to which communicative flexibility is modelled and developed in teaching and learning within their programmes of study.

\section{The experience of international students}

The increase in recruitment of international students and the continuing widening of access for culturally different UK students, would, on the face of it, seem to provide an exciting opportunity to develop in all students, the skills of intercultural competencies. After all, students are exposed to a wide variety of different cultures in their social and academic life, work in multicultural groups and benefit from curricula which are increasingly international in their orientation. However, the substantial body of literature which now exists on the international student experience indicates that this is not yet the case. A great deal has been reported regarding the issue of living and studying abroad from a variety of perspectives. For the purpose of this paper the literature on cross-cultural interactions between international students and host nationals is selected as bearing on the development of intercultural competence.

The literature suggests that the relationship between host nationals and international students may be problematic in several respects: interacting with host nationals in the student and the wider community; working in culturally diverse groups; and relationships with tutors.

Allen and Higgins (1994) and Ames (1996) highlight the reliance on co-national friendships and relationships by international students, particularly when dealing with academic and personal issues. Their findings indicate that once here, mixing with home students and academic problems were the most frequent initial concerns, and that those starting in the second, third and fourth year did not have any significantly different concerns from those starting in year one. Ames' (1996) study revealed that problems of isolation and interacting with home students remained significant after arrival and that second year students experienced more acute levels of concern. Furthermore, according to Allen and Higgins (1994), many had not received a warm welcome from home students or from the community.

The literature stresses the importance of support systems provided through the friendship patterns formed by students. Bochner et al. (1977) provide a model for the development of international students' friendship patterns. They identify three distinct social networks: a primary, mono-cultural network, consisting of close friendships with other compatriots; a secondary, bi-cultural network, consisting of bonds between sojourners and significant host nationals such as academics, students, advisors and government officials and a third, multicultural network of friends and acquaintances.

Bochner et al. (1977) go on to suggest that:

“...mono-cultural (co-national) bonds are of vital importance to foreign students, and should therefore not be administratively interfered with, regulated against, obstructed, or sneered at. On the contrary, such bonds should be and, if possible, shaped to become more open to bi- or multi-cultural influences." (Furnham and Alibhai, 1985:719)

Group work, in particular where the members are from culturally diverse backgrounds, has been the subject of studies by Watson, Kumar and Michaelson (1993). They compared homogeneous and diverse task groups, specifically, 173 upper-level undergraduates who were enrolled in a principles-ofmanagement course, at a large university in the USA. They suggest that culturally diverse groups performed less well than homogenous groups on a variety of tasks where these took place over a time period of nine weeks or less. However, after 17 weeks, the culturally diverse groups performed better than the homogenous groups, particularly in problem identification and problem solving tasks. This study has implications for group working in an academic environment where, as is the case in many British universities, the year is organised into three short terms and the structure of the degree is modular. Students may find themselves on a number of different modules and in several "newly 
formed' groups and may not have the luxury of a 17-week period in which to improve their performance. Further implications for multicultural group working in the classroom were revealed in a recent study carried out by Ledwith et al. (1997) who found that international students working in groups with host nationals perceived UK students generally as exclusive, unfriendly and unwelcoming and that students whose English language skills were perceived as poor were either ignored or excluded from the group process. In addition, some home students felt that international students receive preferential treatment and could be seen as a liability when working in teams (Allen and Higgins, 1994).

The relationship between tutor and student has been documented by a number of writers. Rogers and Smith (1992) have highlighted the fact that many international students regard the tutor/supervisor's role as not being solely concerned with academic issues. A common criticism they found was that the tutors were too preoccupied with their own research to be able to spare any time for the tutees. Research by Allen and Higgins (1994) and Ames (1996) suggests that academic staff require training and development if they are to be effective in their supportive role as counsellor, tutor or supervisor for international students. Cortazzi and Jin (1997), in their study of student/tutor interaction, compared international students' expectations (particularly of Chinese but also of other East- and South-Asian and some Middle Eastern students) with those of their British lecturers and found that they do not always correlate; for example many British lecturers expect students to ask for help if they have problems, whereas the Chinese students expect the teachers, like parents, to show sufficient care and understanding towards their problems and anxieties.

This brief literature review of the international student experience highlights three issues which are examined in the primary research which follows. The literature suggests that interaction between home and international students may be problematic both socially and when engaged in learning tasks. Second, the interactions between international students and their tutors may be subject to unclear expectations held by tutors and students. Third, it suggests that far from enabling students to develop the necessary communicative, cognitive and affective dimensions of their experience, the increasing heterogeneity of the student base may be leading, among the UK majority at least, to entrenched negative stereotypical attitudes and behaviours. How far are these findings replicated in the present research?

\section{Research methodology}

The research undertaken was qualitative and consisted of two separate studies. Over a three year period all new undergraduate international students were interviewed in groups of three or four by one of the researchers who had an administrative role in the school as International Student Tutor. This role had been established in order to provide support to the growing numbers of full-cost international students and students from the European Community, few of whom spoke English as their mother tongue and who also had to adjust to a very different philosophy of higher education. By the end of 1999 international student numbers in the School had increased to two and a half times the number in 1995. Roughly 70 per cent of the students who took part in the research were entering in the first year of the undergraduate programme, and the remaining third were admitted with credit into subsequent years of study.

The interviews were informal, semi-structured conversations lasting for an hour, the purposes of which were twofold: to discover what, if any, concerns students had during their first year of study and to ensure that certain aspects of academic work were understood. Topics covered during the conversations included: comparison of the approaches to learning, teaching and assessment taken in previous educational institutions with that taken in this university; discussion of academic and social interactions with other students; expectations and experiences of social and academic support; and accommodation. The interviews were timed to take place halfway through the first term, so that students would have had some experience of teaching, learning, assessment, and interaction with host students. Each interview started by inviting the students to raise any issues which were causing them 
concern. Once these areas were covered, any remaining topics were raised by the interviewer. Data was collected from a total of 150 students and analysed to identify common themes and experiences.

The semi-structured conversation technique was chosen as the most appropriate for several reasons. In structured interviews of the type commonly used in the context of social surveys there is no long-term relationship between the researcher and the researched. This was not the case here, in that the researcher was a full-time member of staff in the School, although not known to the students at the time of the first interview. The structured interview is a data collection device where the interviewer merely poses questions, formulated in advance, and records answers in a set pattern. This has the advantaged of ease of analysis and comparison between respondents, but is inappropriate where it is feelings, opinions or attitudes which are the focus of the research (Burgess, 1984). However, there are difficulties with using a qualitative approach. In particular, characteristics such as age, social status, gender, race and ethnicity, where these are not shared between the interviewer and the respondent may affect responses (Burgess, 1984). The students were therefore interviewed in groups in order to provide a situation in which the students would have the potential power to define the topics of conversation and to enter into debate and discussion with their peers. The data was then analysed, identifying both common themes and experiences and differences between cultural groups.

In 1998, further research was carried out in the School of Hotel and Restaurant Management to examine the student experience from the viewpoints of international students, home students and teaching staff. Data was collected both by in-depth semi-structured interviews with key informants and by unstructured focus group interviews conducted by one of the researchers who was, at that time, an international postgraduate student in the School. This paper discusses the findings from the three student focus groups. The first group was composed of six volunteers from Sweden, South Africa, Brazil and Zimbabwe. Since there were no volunteers forthcoming from the South-East Asian countries, the second group of six students from South-East Asian cultures was formed through 'snowball sampling'. This method involves using an informant who is asked to put the researcher in touch with a friend who is then asked to participate and to nominate someone else and so on until the required number has been reached (May, 1997). The third group comprised eight home, or UK, student volunteers.

Focus groups are particularly useful where there might be a communication or understanding gap between groups or categories of people or where the researcher wants ideas to emerge from the group. A focus group is a special type of group in terms of purpose, size, composition, and procedures (Krueger, 1994). It is typically composed of seven to ten participants who are selected because they have certain characteristics in common that relate to the topic of the focus group. A permissive environment has to be developed in the focus group to encourage the expression of different perceptions and points of view, without pressuring participants to vote, plan or reach consensus. Careful systematic analysis of the discussions can then provide clues and insights as to how the participants view a particular topic. The discussion is comfortable and enjoyable for participants as they share their ideas and perceptions, at the same time influencing each other by responding to the ideas and comments in the discussion.

The focus group interview works because it taps into human tendencies. Attitudes and perceptions are developed in part by interaction with other people. The deficiencies of face-to-face interviews are that they assume that individuals really do know how they feel and that individuals form opinions in isolation. Both of these assumptions have presented problems for researchers. People may need to listen to opinions of others before they form their own personal viewpoints. Although some opinions may be developed quickly and held with absolute certainty, other opinions may be malleable and dynamic. Evidence from focus group interviews suggests that people do influence each other with their comments, and in the course of a discussion the opinions of an individual might shift. The focus group analyst can thereby discover more about how that shift occurred and the nature of the influencing factors. 
There are limitations to this approach. The researcher has less control in the focus group interview than in a one-to-one interview and has to achieve a balance between being too directive and allowing the discussion to drift aimlessly. In addition to this, the data is more difficult to analyse. For example, care must be taken to interpret comments within their verbal and non-verbal context. In order to provide a check on the interpretation of the focus group discussions, the interviews were recorded, and the facilitator made careful notes of non-verbal signs and gestures against the recording counter. The recordings, transcripts and the notes were then analysed.

\section{Findings}

The experiences expressed in the interviews with the new entrants to the School in the first study were very little different from those of the students who were in their final years of study who took part in the focus groups in the second study. Nor were there significant differences in kind in the experiences of the international students: their comments were similar regardless of particular geographical or cultural background and experience. There were differences in degree, however, particularly between students from a broadly northern European, American or Australian cultural background and those with a Southern European, Asian, Middle or Far Eastern background which will be identified later in the discussion. For the purposes of this discussion the findings from both pieces of research are treated together. Following the pattern of the literature review, their experiences are discussed in three areas: interacting with host nationals; relationships with tutors; and working in culturally diverse groups.

When it comes to issues needing to be resolved in some way, whether academic or personal, the students from the Far East develop strong bonds either with other co-nationals or with other students from the same geographic region. These friendships are very significant for resolving personal matters; many students said that they did not feel comfortable talking with British people about such issues. None of the international students had used the University's support services if they had to cope with personal issues. However, this preference for mono-cultural bonding was equally evident amongst the home students whose friendships and support were with other home students. The preference for mono-cultural bonding was expressed more forcefully in the interviews where without exception all the students said that they felt that the home students were unfriendly. This was felt most strongly by those students from the Far East for whom all interactions with home students seemed to be more problematic; they felt that the home students excluded them socially and academically.

"If there are three or four of them in the group they will talk about what they had seen on television or where they had been the previous night as though we weren't there." (Far Eastern Student)

"If they were in Sweden I would like them to see Sweden and I would expect them to show me their country." (Swedish student commenting on the lack of hospitality shown by British students)

The home students did not seem to share these cultural values regarding the role of 'hosts' or making international students feel welcome ("As guests they should make the effort to socialise"). This raises the question of whether the well documented tendency of international students to remain in their mono-cultural groups is a matter of choice or of necessity, and of course, it suggests that none of the students are benefiting as much as they could from the potential for learning offered by a heterogeneous student population. In Bochner's (1977) terms, there was little evidence of multicultural networks.

Regarding student perceptions of staff attitudes, there were different views among the members of the focus groups. There seemed to be a feeling amongst the home group that some members of staff show favouritism towards high achieving students, rather than towards particular cultural groups. In the international group several students felt that favouritism was shown towards the home or 'white' students and a mature student in the home group also raised this. On the other hand, the Far Eastern group expressed no criticism of staff at all, describing them all as "very nice". This could, of course, be interpreted as confirmation of the theories of writers regarding the degree of 'power distance' when 
it comes to criticising authority (Hofstede, 1994). These students also expressed a greater degree of diffidence about approaching their tutor for help on either academic or personal issues, than students from Northern Europe, which raises questions about how far findings such as those of Rogers and Smith (1992) discussed earlier can be generalised.

The issue that aroused the most heartfelt criticism, however, was that of group working. The home students blamed the international students where group work proved difficult and suggested problems were the result of the poor language skills of international students.

"I personally felt that we suffered as a result of their extremely poor English...why should we have to pass three A Levels to get to university whereas someone who speaks English as a second language they can't structure a sentence, they can't spell and be taking a place in an English university, and they can't obviously handle it and it affect (sic) us." (Home student)

A small number of students were overtly hostile to international students; they felt that there were too many in the School, and that their English was too difficult to understand. Having good written English was not enough, noted one home student:

"When you communicate with me I am not going to say to you

'please write it here because I don't understand'."

There is a link here with the work of Bhawuk (1990) and Triandis (1990) who have commented on the different ways in which those from individualist and collectivist cultures attribute blame. There was little recognition by these students that they might learn something valuable from working with students from different cultures or that different ways of approaching a task might be equally valid. Their major concern was the impact that group work would have on grades and assessment generally and they felt that they were more likely to achieve high marks in mono-cultural groups. The one exception made was for the students from Scandinavia who were seen as clever and hard-working.

"I personally enjoy working with the Scandinavian students who are very bright and also speak good English." (Home student)

The Far Eastern group also expressed concern about group work though this was because they felt ignored within the group when that group included home students. The recollection of their experiences of group working echoes the work of Cox et al. (1991) and Watson et al. (1993) and the issues of multicultural teams. The international student group in particular highlighted the fact that much valuable time is wasted while the group members get to know each other, leaving little time for task completion. There is therefore, a conflict between effective group working and the time scale available to effectively complete the task in hand. These sentiments were also expressed in the interviews, where feelings of exclusion by the home students was a dominant theme, whatever the cultural background of the student.

"When we have to choose other people to work with we are always left to work together, the English students always want to work with their friends." (Spanish student)

Both the interviews and the focus groups revealed significant differences in cultural sensitivity between international students as a whole compared with the UK students. The value of minority views in stimulating group effectiveness (Nemeth, 1986) appears to have been missed by the UK group, who had a tendency to remember the negative aspects at the expense of any positive benefits that might be derived from working in multicultural groups.

"I can understand the theory behind having the opportunity to learn about cultural awareness and its value within the industry but in practice it's just a pain." (Home student)

The international students were more sensitive to and understanding of the needs of students from different countries, including the UK, than were the UK students and in the interviews in particular, 
expressed a desire to use the opportunity of studying in a foreign country to learn more about cultural differences. They felt, irrespective of nationality, that the UK students are not as prepared as perhaps they ought to be to interact effectively with international students.

"Even though the UK is so multicultural, I find that the students are unprepared...they are used to the different races who have been here many years and who have adapted to the British ways...but yet they have a problem with us who have a strong culture." (Malaysian student)

They commented that the smaller the culture distance between the UK and international students, the more comfortable the UK students appear to be. This was confirmed by the comments of the UK group who spoke in very favourable terms, in particular, of the Scandinavians because of their command of the English language and what was perceived as their intellectual ability.

\section{Discussion}

This research confirms the literature on intercultural competence which indicates that contact alone is not sufficient to encourage the development of cultural awareness, cultural sensitivity and communicative flexibility. Indeed, it may instead reinforce damaging cultural stereotypes. Whilst undergraduate hospitality programmes commonly include education on the cognitive level (for example including modules on management 'best practice' in areas such as equal opportunities, managing diversity, conducting appraisals, team work and leadership, performance management, recruitment and selection and so on), the inclusion of training in intercultural competency is less common.

The literature suggests that training can be effective (Brislin et al., 1986; Mendenhall and Oddou, 1985; Trompenaars and Woolliams, 1999; Harris and Brewster, 1999), but that raising cultural awareness through internationalising the curriculum and providing information about different cultures needs to be accompanied by more experiential training. Experiential learning activities are based on the theory that students will assimilate information more easily if it is accompanied by experiences such as simulating critical incidents and reflecting on responses (Brislin, 1986). Such training, whilst it may encourage reflection of a students' own cultural values and responses to different cultures, is not aimed at transforming individual personalities or character but at adding on social skills. Furnham and Bochner (1986:241) point out that 'interpersonal difficulties across cultural boundaries stem from the participants not possessing the requisite social skills', and not primarily from personal deficiencies.

Based on these ideas, students on a Masters programme in International Management in the School take part in a module designed to provide them with this reflective experiential learning. Student evaluations of this module confirm that they felt it was valuable in helping them to develop their intercultural competencies. Ledwith and Seymour (2001) report on the success of another initiative in a Business School which was designed to develop in students, their ability to respect and work with multicultural differences. Serrie (1992) provides further support for the view that intercultural management competencies can be developed within higher education through techniques which provide experiential learning. It thus seems clear that if hospitality degree programmes are to provide the industry with future managers who are able to operate effectively in a culturally diverse context, they must include as part of a compulsory core, training in intercultural competence for all students and that intercultural competence should be included in graduate profiles.

However, it is clear that there is a need for training and coaching in cross-cultural team-working skills, not only for students, but also for staff. Therefore, following these findings, a continuing programme of staff workshops has been developed in the School, covering issues around teaching and learning in culturally diverse groups. These include all members of staff within the School: academic, technical, administrative and clerical. A self-assessment questionnaire was developed and given to staff at the beginning of the first workshop to encourage reflection on responses to the multicultural student body. Following this, staff took part in an exercise based on the critical incidents techniques of intercultural 
competence training developed by Brislin et al. (1986). Critical incidents were developed, drawing on actual events in the School. Staff discussed these incidents in small groups, exchanging views on the causes of the problems and on possible solutions. Out of these evaluations further suggestions for future training and changes to School policy were developed, building on the School's new approach of polycentricity. These are now in progress and cover staff training, student induction, and training for students in how to work effectively in groups.

Finally, an initiative to encourage discussion and exchange of ideas about models of learning and teaching has been put into place which involves continuous peer observation and feedback. Staff work in groups of three to observe and give feedback to each other on individual teaching and learning sessions. School-wide discussions also take place on ways in which to overcome ethnocentricity in module content, teaching and learning and assessment procedures.

\section{Conclusion}

The development of intercultural competence in undergraduate students would seem to be contingent on the extent to which communicative flexibility is modelled and developed in learning and teaching within programmes of study, particularly in classroom activities. This requires an approach which builds on the current experiences of students by providing opportunities to engage in reflective experiential learning so that all students develop their cultural awareness and their intercultural competence. Without such efforts there is a danger that the increasing heterogeneity of the student body will lead to entrenched stereotypical attitudes, rather than increased cultural sensitivity. However, this kind of learning can be uncomfortable not only for students, but for staff, and there is a clear need for the provision of systematic training and support for all staff in the development of their own cultural awareness and communicative flexibility. Finally, careful thought must be given to the design of programmes and modules to ensure that research evidence on the efficacy of working in multicultural groups is taken into account in the requirements for assessed group work.

Given the increasing mobilisation of the international work force and the internationalisation of business, it is essential that graduates are interculturally competent. The increasing heterogeneity of the student body provides an opportunity to develop these skills, but if the potential for learning afforded by the increasing cultural diversity of the student body is not tapped in this way, then the opportunity to produce culturally competent managers for the hospitality industry will be a wasted opportunity.

"One of the best ways to have cross-cultural learning and crosscultural research is through extensive interactions with international students. Their presence provides an extraordinary learning opportunity that is all too often neglected. Through our mutual interactions, we can ...more effectively prepare ourselves for future careers with multi-cultural and international dimensions. The opportunity for personal and professional growth is profound." (Paige, 1990:182). 


\section{References}

Allen, A. and Higgins, T. (1994) Higher Education: the international student experience. Heist in association with UCAS.

Ames, M. (1996) Oxford Brookes: the international student experience. Oxford Brookes University.

Amir, Y. (1969) Contact Hypothesis in Ethnic Relations. Psychological Bulletin 71, 319-41.

Bhawuk, D. P. S. (1990) Cross-cultural Orientation Programmes. In R.W. Brislin (ed.) Applied Crosscultural Psychology. Beverly Hills, CA: Sage, 325-346.

Black, J.S. and Mendenhall, M. (1991) A Practical but Theory-based Framework for selecting CrossCultural Training Methods. In M. Mendenhall and G. Oddou (1991) International Human Resource Management. USA: Wadsworth.

Bochner, S. (1982) Cultures in Contact: studies in cross-cultural interaction. Pergamon Press.

Bochner, S., McLeod, B. and Lin, A. (1977) Friendship Patterns of Overseas Students: a functional model. In A. Furnham and N. Alibhai, op cit, 711; 719-720.

Brewster, C., and Harris, S (1999) International Human Resource Management: contemporary issues in Europe. London: Routledge.

Brislin, R. W., Cushner, K., Cherrie, C. and Yong, M. (1986) Inter-cultural Interactions: a practical guide. Beverly Hills, CA: Sage.

Burgess, R.G. (1984) In the field: An introduction to field research. Allen \& Unwin, London.

Chen, C. and DiTomaso, N. (1996) Performance Appraisal and Demographic Diversity. In E. Kossek and S. Lobel, Managing Diversity. Oxford: Blackwell.

Cortazzi, M. and Jin, L. (1997) Learning Across Cultures. In McNamara and Harris, op cit, 76-90.

Cox, T. H., Lobel, S. A. and McLeod, P. L. (1991) Effects of Ethnic Group and Cultural Differences on Co-operative and Competitive Behaviour on a Group Task. Academy of Management Journal 34(4), 827-847.

Furnham, A. and Alibhai, N. (1985) The Friendship Networks of Overseas Students: a replication and extension of the functional model. International Journal of Psychology 20, 709-722.

Furnham, A. and Bochner, S. (1986) Culture Shock: Psychological reactions to unfamiliar environments. London: Methuen.

Harris, H. and Brewster, C. (1999) An integrative framework for pre-departure preparation. In C. Brewster and H. Harris, International HRM: Contemporary Issues in Europe. London: Routledge, 223-240.

Hofstede, G. (1994) Cultures and Organisations: software of the mind. London: Harper Collins.

Jupp, T. C. and Roberts, C. (1982) Language and Disadvantage. In J. J. Gumperz, Language and Social Identity. Cambridge: Cambridge University Press.

Knapp, K., Enniger, W., Knapp-Pottof, A. (1987) Analyzing Intercultural Communication. Mouton de Gruyter

Ledwith, S., Lee, A., Manfredi, S. and Wildish, C. (1997) Multi-Culturalism, Student Group Work and Assessment. Oxford Brookes University.

Ledwith, S. and Seymour, D. (2001) Home and Away: preparing students for intercultural management. International Journal of Human Resource Management 12(8).

May, T. (1997) Social Research: issues, methods and process. Buckingham: Open University Press.

Mamman, A. (1995) Employee intercultural effectiveness in a multicultural workplace: theoretical propositions, strategies and direction for future research. International Journal of Human Resource Management 6(3) September.

Meddenhall, M. and Oddou, G., (1985) The dimensions of expatriate acculturation: a review. Academy of Management Review 10(1), 39-47.

Nemeth, C. J. (1986) Differential Contributions of Majority and Minority Influence. Psychological Review 93(1), 23-32.

O'Driscoll, M., Haque, A. and Oshako, T. (1983) Effects of Contact and Perceived Attitude Differences on Social Distance among Australian, Japanese and Pakistani Students. Journal of Social Psychology 120, 65-72.

Paige, R. M. (1990) International Students: cross-cultural psychological perspectives. In R. W. Brislin (ed.), Applied Cross-cultural Psychology. Beverly Hills, CA: Sage, 161-185. 
Rogers, C. and Smith, P. (1992) Identifying the Needs of Overseas Students: A monitoring exercise at the University of Southampton. The Journal of International Education 15(4), 417-432.

Ruben, B. D. (1976) Assessing Communication Competency for Intercultural Adaptation. Group and Organisational Studies 1, 334-54.

Serrie, H. (1992) Teaching Cross-Cultural Management Skills. Journal of Teaching in International Business 3(3), 75-91.

Trompenaars, F. and Woolliams, P. (1999) Transcultural competence. People Management April 22, 36-37.

Tung, R. L. (1984) Strategic management of human resources in the multinational enterprise. Human Resource Management 23(2), 129-143.

Tung, R. L. (1988) The New Expatriates. Cambridge MA: Ballinger.

Watson, W. E., Kumar, K. and Michaelson, L. K. (1993) Cultural Diversity's Impact on Interaction Process and Performance: comparing homogeneous and diverse task groups. Academy of Management Journal 36(3), 590-602. 